\title{
Effects of Directional Decisional Support Upon Risk Taking Online
}

\author{
James G. Phillips ${ }^{*}$, , Adrian L. Laughlin ${ }^{1}$, Rowan P. Ogeil ${ }^{1}$ and Alex Blaszczynski ${ }^{2}$ \\ ${ }^{1}$ School of Psychology and Psychiatry, Monash University, Australia \\ ${ }^{2}$ School of Psychology, University of Sydney, Australia
}

\begin{abstract}
Decision-aids can be used to inform, but may also influence, decision-making. The present study considered whether a decision-aid which provided biased/directional information was capable of influencing decision-making toward a specific alternative online, and whether time pressure and risk would influence the use of that decision aid. To evaluate factors influencing the efficacy of a directional decision aid, twenty-four participants played computerised Blackjack whilst provided with advice that was capable of minimising losses (Basic strategy), under differing levels of risk and time pressure. The advice was directional (only advising to draw cards, or only advising to stand). Biased information influenced card totals. "Conservative" (stand) advice led to lower wagers and hesitation before placing bets. Participants responded faster at higher levels of risk and compliance with the aid seemed greater at higher risk. Decision aids can influence behaviour, but their impact may depend upon time pressure and risk.
\end{abstract}

Keywords: Decision making, risk, gambling, recommenders, decision aid.

The internet and mobile phone have increased consumer access to a variety of services $[1,2]$ including products such as gambling [3-5], hence the internet has attracted the attention of regulators [6-8] over issues such as advertising $[9,10]$. To advise and inform policy makers and regulators, the present study considered factors such as risk and time pressure that might affect the potential influence of onscreen messaging.

\section{RECOMMENDERS}

Although the internet and mobile phone potentially increase access to consumers, they also place an organisation's competitors just another click away [2]. Hence, some organisations use recommender technology to support consumer activities [11]. A recommender agent is an application that assists consumer decision making by providing information about the various alternatives available or by suggesting a specific alternative. For example, shopping websites such as Ebay and Amazon suggest items which the buyer may be interested in purchasing based on a personally input profile of interests or previous purchase activity. Recommender technology supports consumer behaviour and builds customer loyalty by assisting consumers to navigate product information spaces by suggesting items of potential interest [12]. Such recommenders provide their advice on the basis of content (e.g. keywords) or the behaviour of other similar consumers (e.g. people who bought this item also bought that item), or a combination of both sources of information [11].

\section{TIME PRESSURE}

When considering any attempts at online influence, it must be made clear that consumers are moving targets.

*Address correspondence to this author at the School of Psychology and Psychiatry, Monash University (Bld. 17), Clayton, VIC, 3800, Australia; Tel: +6139905-3914; Fax: +61399053948;

E-mail: Jim.Phillips@med.monash.edu.au
Trends and fads change [13]. Consumers can be tracked as they navigate through commercial websites [14], and dwell time and number of clicks can be related to probability of purchase [14]. The potential impact of any recommendation is also dependent upon its' source, the product, and the number of previous recommendations [15]. The potentially dynamic nature of online influence [16] will become even more apparent as systems incorporate geolocation technology. Individually customised, location-aware messages about events, activities, products and special offers can be sent to consumers in order to influence decisionmaking behaviour in real-time $[17,18]$. It is claimed that due to the real-time and individualised aspect of this messaging, recommender technology can be more pervasive and may also be more influential than advertising [18].

\section{BIAS}

Recommender technology is typically used to support and encourage consumer behaviours [16], but recommender systems are not necessarily unbiased in their operation and are prone to a variety of attacks [19] where individuals seek to encourage or discourage consumers from purchases by influencing consumer ratings of products. Indeed, although there is considerable technical effort devoted to the influence of purchasing behaviours, there is appreciably less effort devoted to attempts to warn and protect consumers [20,21].

Some forms of decisional support have been proposed to better inform consumers $[20,22]$. Commercial regulators and government departments are generally concerned with issues such as consumer protection and ensuring that consumers' choices are informed [23]. An example of this is the use of decision-aids in gambling environments. Several authors $[20,23,24]$ have discussed the introduction of strategies to inform gamblers of the risks involved with excessive gambling. Previous attempts to influence online gambling behaviour have used banners and "pop-ups" involving a variety of onscreen warnings, with messages 
addressing the nature of probability, or reminders that gamblers' check their spending limits. Such strategies include displaying digital messages such as 'Don't gamble more than you can afford' between hands of table games and the use of odds displays to inform individuals of their chances of winning [20]. Evaluations of these interventions focus upon whether the messages were seen or recalled. Use of such technology has been somewhat successful in limiting excessive gambling behaviour [24], but more research is required to address the potential effectiveness of such aids in real-time dynamic environments [24, 25].

Decision aids do not just have potential roles encouraging consumers but may also have roles informing and advising. Hence there is a need to examine their potential to influence, as well as identify factors that might reduce their efficacy. In a study of electronic recommender agents, Haubl and Murray [26] found that the provision of biased information could influence customer preferences. By using a recommender agent which focused on a specific attribute of various alternatives, Haubl and Murray [26] showed that the preferences of shoppers could be influenced toward consideration of that attribute as the primary attribute. Therefore, the electronic recommender agent was able to influence customer purchases through manipulation of perceived attribute importance. Furthermore, these preferences were maintained even when the aid was not present. Haubl and Murray [26] postulated that the primary reason for this was that the consumers deemed the recommender to be a neutral source of information and that it was only logical to assume that the recommendations provided were provided with good reason. Indeed, as other authors note [27], for an electronic aid to be persuasive, it must appear to be relevant and transparent. That is, the recommendation device should appear to benefit the decision-maker and there should be obvious logic behind the recommendation $[27,28]$.

\section{ONLINE DECISIONS}

There are a variety of ongoing attempts to electronically influence the consumer, that take into account content (i.e. content based recommenders) and the behaviour of one's peers (i.e. collaborative filters) [11]. In addition, the consumer is not simply making a decision on the basis of how a purchase is framed, but can also undertake their own processes of search and deliberation $[14,15]$. Under such circumstances the consumer could be considered to be a decision maker with varying amounts of time to weigh the evidence for or against a decision against their own personal criterion $[29,30]$.

A variety of stochastic/evidential models of decision making are liable to be able to explain how people evaluate information and select options [29]. These models of decision making explain increased caution as a function of more stringent criteria adopted for a decision (i.e. more evidence required), and can account for changes in quality of decision making as a function of the time available [29]. With less time available, less evidence is processed and as decisions are less informed, they are more subject to error. Stochastic/evidential models of decision making can also account for bias in decision making by postulating differential thresholds for "pro" and "con" decisions. A lower criterion threshold for evidence associated with a "pro" decision will lead to a greater proportion of "pro" responses.

The present study seeks to understand how online decisions might be influenced by biased information and factors such as risk and time pressure. As an experimental paradigm for addressing online choice behaviour [31], the present study used the game of Blackjack. Blackjack is a card game played against a dealer. The object of the game is to attain a total as close to 21 as possible, without exceeding 21 (busting), that also exceeds the total attained by the dealer. In casinos the dealer has to draw cards until a total of 17 or greater is reached. For the player the game involves several decisions; namely the wager, and then the decision whether or not to draw cards. In this game, less than optimal behaviour can reduce a player's chances of winning.

Blackjack is available in online forms, and while there is a recommended strategy to minimise loss called Basic [32], people are known to engage in less than optimal behaviours when playing Blackjack in gaming venues [33] and online settings [34]. Games such as Blackjack and poker [35] are convenient and more realistic (and less susceptible to ludic fallacy) than some other laboratory models of decision making, as skill can improve the likelihood of winning, but any outcomes still retain appreciable chance elements. In such games player behaviour may vary as a function of involvement, degree of risk and opportunity for deliberation $[31,35,36]$.

There are a variety of reasons for less than optimal play in Blackjack. Players may be ignorant of Basic [34], and hence may benefit from decisional support. In addition, there are elements of an approach/avoidance conflict in Blackjack as the player is required to obtain a total less than 21 , while beating the dealer's total. Within gaming venues and when playing for money, players are reluctant to draw further cards (fail to hit error) [33]. When playing for points online, players tend to draw cards when the odds are actually in their favour (fail to stand) [34]. Given that there are variations in willingness to approach or avoid in terms of willingness to choose cards in the game of Blackjack, it is of interest to determine whether online advice can influence player behaviour.

\section{INFLUENCE OF DECISIONAL SUPPORT}

An important consideration for both commercial organisations and regulators is whether online advice can influence approach or avoidance behaviour. It is of specific interest to determine whether messages encouraging or warning consumers online in real time can influence their choices. In addition, it is important to understand the circumstances (i.e., time pressure; risk) under which online advice can influence consumer use of electronic services [36-38]. The present study used Blackjack as a laboratory model of consumer behaviour, varying the speed and the levels of risk associated with the game. To simulate online inducements, in some conditions advice was only given when Basic recommends that people draw extra cards (i.e., hit). To simulate online advisory warnings, in some conditions advice was only given when Basic recommends that people do not draw further cards (i.e., stand). It was expected that advice with a directional component would 
sway play in the recommended directions, namely a greater willingness to approach a card total of 21 when only advised to hit, or a reluctance to approach a card total of 21 when only advised to stand. The influence of online messaging as a function of time pressure and degree of risk would be inferred from the card totals that players draw and stand upon. Average wagers were used as an index of consumer confidence. Response times were measured to monitor the processing of advice.

\section{METHOD}

\section{Participants}

Participants were 24 university students $(M=22.21$ years, $S D=4.81$ years) who varied in gambling experience, but had gambled previously in a casino setting. Individuals with no gambling history or a history of gambling related problems were excluded from participation for ethical reasons. Participants received no remuneration for their participation.

\section{Apparatus and Task}

The game of blackjack was played on a Pentium 4 IBM compatible Personal Computer on custom written software that dealt cards and timed responses using assembly code. The computerised version of Blackjack resembled the game played on standard layouts in casinos except there was no provision for doubling or splitting.

A short tone signalled the beginning of each hand. The message "Place your bet now" then appeared on the screen and participants entered their wager (1-9) using the number pad. To manipulate the degree of risk, the number of points associated with a unit wager was varied between conditions. In the low risk condition the value of the wager was multiplied by 2 , and for the high risk condition the value of the wager was multiplied by 10 .

After wagering some points, the player and dealer received their card(s) in the bottom-left and top-left of the screen respectively and the hand totals appeared above the respective cards. Participants were then required to decide whether to refuse further cards (stand) by pressing the space bar, or choose another card (hit), by pressing any other key. The experimental conditions manipulated time pressure; in the fast condition decisions were required within 1 second, whereas in the slow condition decisions were required within 3 seconds. Where a response was not forthcoming, the defaults applied. Defaults were a minimum bet and drawing another card.

When appropriate, advice appeared in the centre of the screen ("Advised to hit" or "Advised to stand"), and was refreshed after each card was dealt. To evaluate the potential influence of decision aids, in some conditions participants only received hit advice within a given block of trials; in other conditions participants only received stand advice. For each condition, the advice was always correct according to Basic strategy [32] and was based upon the player and dealer card totals (see Table 1). For example, in the Hit advice condition, participants received only hit advice, but only when it was appropriate, and when the correct decision according to Basic was to stand, no advice was provided.
Table 1. Basic Blackjack Strategy (Thorp, 1966)

\begin{tabular}{|c|c|c|c|c|c|c|c|c|c|c|c|}
\hline \multicolumn{12}{|c|}{ Dealer's Up-card } \\
\hline \multirow{7}{*}{ 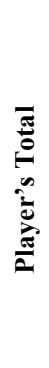 } & & 2 & 3 & 4 & 5 & 6 & 7 & 8 & 9 & 10 & $\mathbf{A}$ \\
\hline & 12 & H & H & $S$ & $S$ & $S$ & $\mathbf{H}$ & $\mathbf{H}$ & $\mathbf{H}$ & $\mathbf{H}$ & $\mathbf{H}$ \\
\hline & 13 & $S$ & $S$ & $S$ & $S$ & $S$ & $\mathbf{H}$ & $\mathbf{H}$ & $\mathbf{H}$ & $\mathbf{H}$ & $\mathbf{H}$ \\
\hline & 14 & $S$ & $S$ & $S$ & $S$ & $S$ & $\mathbf{H}$ & $\mathbf{H}$ & $\mathbf{H}$ & $\mathbf{H}$ & $\mathbf{H}$ \\
\hline & 15 & $S$ & $S$ & $S$ & $S$ & $S$ & $\mathbf{H}$ & $\mathbf{H}$ & $\mathbf{H}$ & $\mathbf{H}$ & $\mathbf{H}$ \\
\hline & 16 & $S$ & $S$ & $S$ & $S$ & $S$ & H & H & $\mathbf{H}$ & $\mathbf{H}$ & $\mathbf{H}$ \\
\hline & 17 & $S$ & $S$ & $S$ & $S$ & $S$ & $S$ & $S$ & $S$ & $S$ & $S$ \\
\hline
\end{tabular}

Once players had chosen to stand or had busted, the computer automatically dealt cards for the dealer. As per casino procedures the dealer was dealt cards until a card total above 16 was obtained. At the completion of the hand, participants were informed of the result of the hand via an on-screen message. The amount won or lost on that hand and amount won or lost so far in that block of trials appeared along the bottom of the screen.

\section{Procedure}

The experimenter explained the rules of the simulated version of Blackjack and described the eight experimental conditions to the participants. The experimenter then informed participants that they should attempt to win as many points as possible. Participants were also informed that Basic advice would appear on the monitor in some instances and were told that this advice was "good advice". However, participants were not given any instructions regarding adherence to the advice. Participants then completed 24 practice trials to familiarise themselves with the apparatus and task. The practice trials commenced with six trials using a seven second time limit that enabled the experimenter to re-explain several aspects of the task while the participant engaged in the task. Participants then completed the eight conditions each containing 30 hands for a total of 240 hands of Blackjack.

At the beginning of each condition participants were alerted to the specific time and risk parameters for that experimental condition via on-screen messages ("You will have $X$ seconds to decide" and "Bets will be multiplied by $X$ '). Risk level was also signified by screen background colour (green for low-risk, blue for high-risk). No notification of advice condition was given as the advice, where appropriate, appeared in the centre of the screen ("Advised to hit" or "Advised to stand"). At the completion of the hand, participants were informed of the result of the hand via an on-screen message. The amount won or lost on that hand and amount won or lost so far in that block of trials appeared along the bottom of the screen.

The computer recorded the amount wagered, the totals hit and stood on, response times for each card, and deviations from Basic strategy for each hand. Experimental conditions 
were separated by twelve seconds to provide a short rest interval. The order of presentation of conditions was controlled using a Latin Square to control for order effects and fatigue. After participants had completed the experiment they were debriefed regarding the dangers of gambling and the negative expected outcome associated with all forms of gambling in the long term.

\section{Design and Analysis}

The experiment was a $2 \times 2 \times 2$ Speed (one or three seconds) by risk (wagers multiplied by two or ten), by advice (hit only or stand only) repeated design. To test decision-aid influence, participants received only either hit or stand advice within a given block of trials. To measure the influence of the decision aid, the mean total at which participants drew their last card were analysed. Mean bet sizes were used as an index of consumer confidence. To introduce the element of time pressure response deadlines were implemented, after which time default responses were registered. Analyses address overall performance, and include defaulted trials, as such reflects practice in gaming environments where minimum bets are required to stay in the game.

\section{RESULTS}

Participants' behaviour was recorded and means were subsequently calculated and analysed using SPSS v17. To explore the effects of directional advice, the average total that participants drew their last card on was analysed. This variable was selected for analysis (rather than average standing total) because it was sensitive to caution [31] and thus likely to be influenced by the advice manipulation. An effect of speed was discovered. When given one second to decide, participants drew their final card on a higher total $(M=11.83, S E=0.16)$ than when given three seconds to decide $\quad(M=11.37, \quad S E=0.16), \quad F(1,23)=15.633, \quad p<.001$, $\eta^{2}=.41$. An effect of advice was also discovered. Participants drew their last card at a lower total when only stand advice was given $(M=11.41, S E=0.17)$ than when only hit advice was given $(M=11.79, S E=0.15), F(1,23)=24.691, p<.05$, $\eta^{2}=.52$. There was no effect of risk and no significant interactions.

Participants' behaviour was clearly influenced by directional advice. The time participants took to select cards may also offer insights as to their response to advice. Unless they obtained Blackjack, participants were asked whether they wanted another card, and this time was measured. There was an effect of speed upon the time participants took to select cards $\left(F(1,23)=14.953, \quad p<.001, \eta^{2}=.39\right)$, with participants taking less time to respond in the 1 second $(M=722 \mathrm{~ms}, S E=23)$, than the 3 second $(M=945 \mathrm{~ms}, S E=73)$ condition.

The degree of risk also influenced the time to select cards $\left(F(1,23)=6.712, p<.05, \eta^{2}=.23\right)$. Participants took less time to select cards at higher risk $(M=818 \mathrm{~ms}, S E=46)$ than at lower risk $(M=849 \mathrm{~ms}, S E=46)$. An interaction between speed and risk approached significance $\left(F(1,23)=3.986, p=.058, \eta^{2}=.15\right)$, and may be seen in Fig. (1). Even when more time is available, it seems that participants were taking less time to select cards in the high risk condition (Mean Difference $=202 \mathrm{~ms}$ ) than the low risk condition (Mean Difference $=245 \mathrm{~ms}$ ).

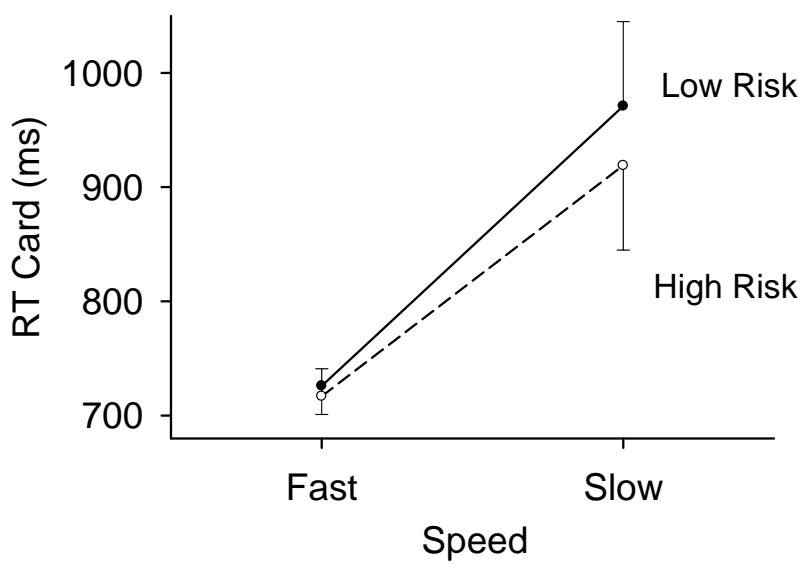

Fig. (1). Effect of speed of game and risk upon mean time to choose cards (ms).

As a potential index of consumer confidence, average bet size was analysed to determine whether participants wagering decisions were influenced by risk and speed. The results showed that participants wagered more points per hand under the three second conditions $(M=5.78, S E=0.34)$ than under one second conditions $(M=4.77, S E=0.30)$, $F(1,23)=15.055, p<.05, \eta^{2}=.40$. Participants also selected higher numbers for wagers under low-risk conditions $(M=$ 5.79, $S E=0.29)$ than under high-risk conditions $(M=4.76, S E$ $=0.34), F(1,23)=17.212, p<.05, \eta^{2}=.43$. There was also a significant advice by risk interaction $F(1,23)=4.347, p<.05$, $\eta^{2}=.16$, that may be seen in Fig. (2). Online inducements or warnings may influence consumer confidence, but the effect may be a function of the perceived risk of the activity.

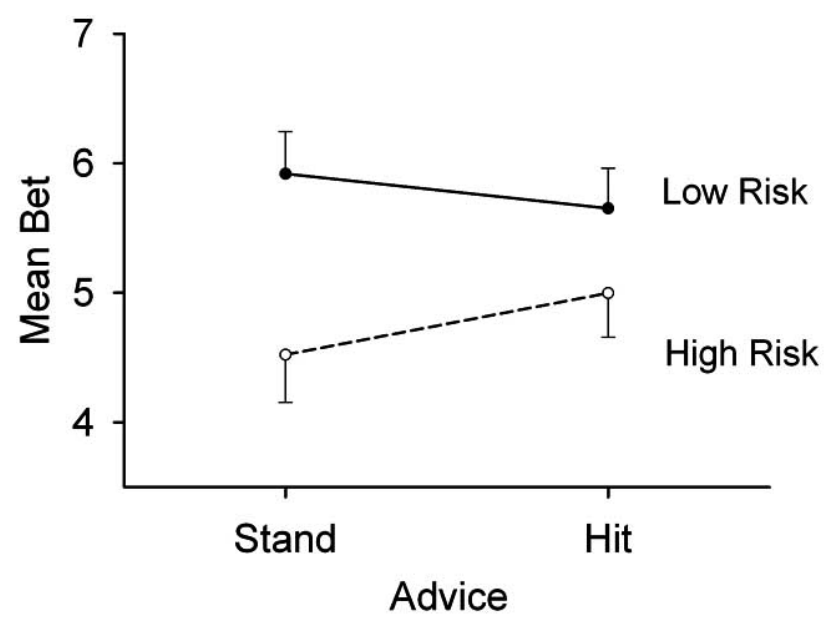

Fig. (2). Effect of risk and directional advice upon mean bets.

To understand how participants' decision processes were influenced by the availability of directional decisional support, the times required to place bets was analysed. As expected, there was a significant effect of speed upon the time required to place bets $\left(F(1,23)=4.863, p<.05, \eta^{2}=.18\right)$. Participants placed bets faster when they were only given 1 second to place bets $(M=397 \mathrm{~ms}, S E=30)$ than when they were given 3 seconds to place bets $(M=467 \mathrm{~ms}, S E=36)$. However this effect should be viewed in light of its possible interactions between risk and advice. 
An interaction between the effects of speed and advice approached significance in its effects upon the time spent to place bets $\left(F(1,23)=4.061, p=.056, \eta^{2}=.15\right)$. As may be seen in Fig. (3), when the game was faster participants appeared to be spending less time considering their bets when Hit advice would be available (Mean Diff $=-109 \mathrm{~ms}$ ) than when Stand advice (Mean Diff=-31ms) would be available. This may be because Stand advice could be construed as urging caution.

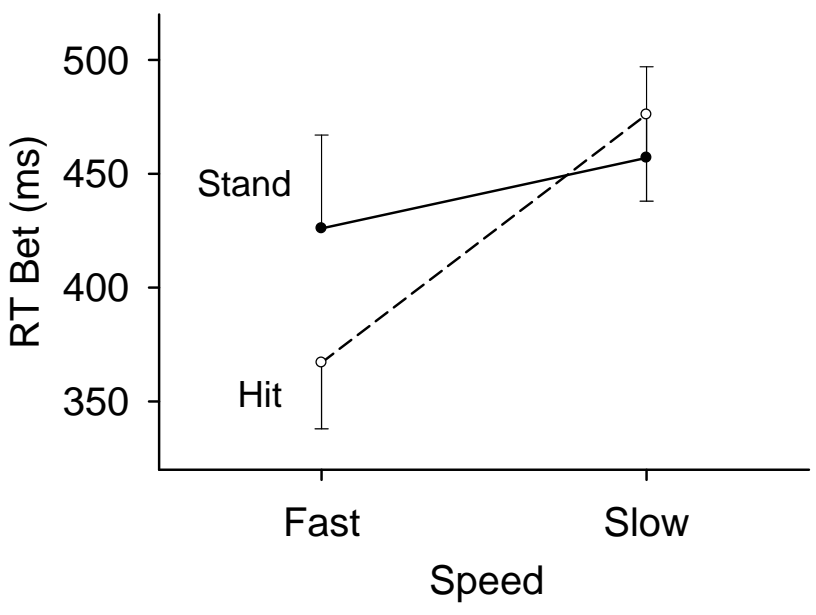

Fig. (3). Effect of speed of game and directional advice upon mean time to place bets $(\mathrm{ms})$.

Although there were suggestions that people may have been attending more to a specific form of advice, risk appeared to affect the processing of advice. There was a significant interaction between the effects of speed and risk upon the time spent to place bets $(F(1,23)=13.640, p<.001$, $\eta^{2}=.37$ ). As may be seen in Fig. (4) participants appeared to be spending less time thinking about placing wagers when there was a greater level of risk.

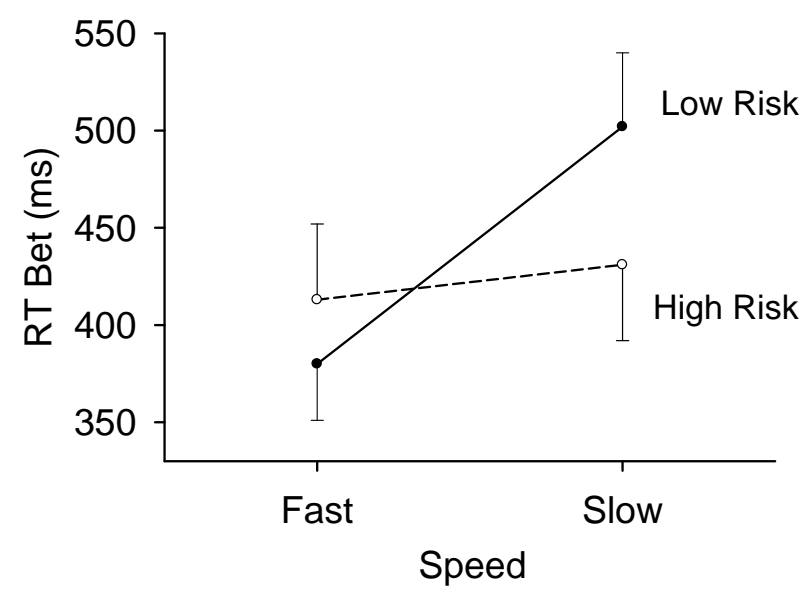

Fig. (4). Effect of speed of game and risk upon the mean time to place bets (ms).

\section{DISCUSSION}

The present study aimed to determine whether online advice with a directional component could sway a person's decisions in a specific direction, and examined factors influencing compliance with such advice. To accomplish these aims the study required participants to play a computerised version of the casino game Blackjack in which the decision aid only supplied advice of a specific form (hit or stand) while also manipulating factors such as time pressure and risk that might influence use of the decision aid. Online advice was shown to be capable of influencing player behaviour in specific directions. Advice that was designed to minimise loss (Basic) but directed just towards hitting or standing, swayed players towards greater or lesser card totals. At higher risk, the decision aid also influenced wager size. At higher risk, recommendations to stand and to avoid higher card totals were accompanied by lower wagers, while recommendations to hit and approach higher card totals were accompanied by higher wagers. This indicates that online advice can have a potential role influencing consumer behaviour. However context may also influence consumer behaviour, as increased risk actually reduced the amount of time players spent on their decisions.

\section{BIAS}

Directional advice influenced card totals. Stand advice led to greater caution, with participants drawing their last cards at lower totals. Hit advice led to greater risk taking as last cards were drawn at higher totals. Wager size was analysed as an index of player confidence. At higher risk the advice to draw more cards and approach a card total of 21 encouraged greater wagering behaviour, while at lower risk the advice to stand and not draw more cards reduced wagering behaviour. Hence the directional decision aid influenced player behaviour, encouraging not just a greater willingness to risk higher card totals approaching 21 but also greater wagering in the hit condition. In the stand condition the directional decision aid discouraged the risking of higher card totals, and also reduced wagering in the stand condition. Presumably the decision aid focussed attention upon specific task attributes [26] such as the need to approach 21 and take risks (or a need to avoid 21, be cautious and avoid busting) [33] and this concern to approach or avoid higher totals extends towards other behaviours such as wagering.

\section{TIME PRESSURE}

The ability to utilise decisional support may also depend upon the context under which it is provided [39]. The quality of a decision is known to improve with the time available to make it [29]. It was noted that the decision-aid was less influential under increased time pressure, and players spent less time on their decisions at higher levels of risk. Indeed, some researchers suggest a scarcity of resources associated with higher risk can lead to panic and a poorer evaluation of available information and options [30, 40, 41]. Such data are in keeping with observations that simplified decision-making strategies (e.g., elimination by aspects) that focus on the most important attributes or piece of information available $[39,42]$ are often used under time pressure. There may be circumstances associated with greater cognitive demand where a decision aid might be more influential. For instance, Sarter and Schroeder [43] and Todd and Benbasat [44] found that in situations of greater cognitive demand associated with time pressure, that a decision-aid could be more influential if perceived to be reliable. This was presumably because the decision aid was seen as providing important information. In the present study the conservative advice to stand and draw 
no more cards led to reduced wagering and slowed the speed with which people placed bets, but time pressure and risk also influenced decisions.

\section{COMPLIANCE}

In the current study the average percentage of Basic errors was $24.2 \%$. The consequence of departures from Basic strategy is to concede a greater advantage to the casino [45]. Although Basic is a strategy that minimises loss, players are known not to comply with Basic [33, 46], this may arise from a fear of obtaining a total greater than 21 and busting [33] or from ignorance [46]. As Basic is not automatically followed even when immediately available [34], it is likely that players do not judge the strategy as sufficiently reliable [28]. For instance Horst et al. [37] found online services provided by the government were not utilised by individuals if the service not perceived as trustworthy. Indeed other studies using Blackjack have suggested that personalised strategies may be preferred in the face of losses [31].

In the present case the decision aid was supplying limited but faithful information as to behaviours that would minimise loss, but that does not mean consumers will necessarily follow such aids. At high risk people wagered less when advice to stand was delivered. This indicates that online warnings can be a useful consumer aid. However, at low risk people tended to wager more when advice was to stand. This indicates that warnings can be less efficacious when a situation is perceived as low risk or that warnings may be discounted by a risk taker. In other words there is the potential for consumers to ignore and be emboldened by warnings when the situation is regarded as "low risk".

Consumers may evaluate the decision aid in terms of its prior performance or the extent to which they agree with the aid [28], and a variety of factors may influence their ability to evaluate the decision aid. For example, Haubl and Murray [26] and Gretzel and Fesenmaier [27] suggest that perception of the source of the information is a factor which dictates how influential a decision-aid may be. Also, for a decisionaid to be perceived as the primary information source, the individual needs to understand the relevance or logic behind the decision $[27,28,47]$. Therefore, for a decision-aid to be informative or influential even under situational constraints, developers of decision-aids need to ensure that decision-aids are perceived as trustworthy and the reasoning behind the advice given is clearly understood by the individual before the aid is presented [48, 49].

For instance, O'Hare and colleagues [50] used a Blackjack game with full Basic advice and found compliance with Basic advice was significantly correlated with levels of logical reasoning ability, and varied with educational attainment. In the present study there were indications that confidence associated with the decision aid advice might vary as a function of risk $[36,38]$.

\section{DECISION AID INFLUENCE}

Overall, the findings provided support for the assertion that decision-aids are capable of influencing decisionmaking. There was not a complete compliance with Basic, suggesting that individuals may have been utilising personalised blackjack strategies. However, the finding that participants' average drawing totals were influenced by advice direction suggests that some amount of influence can be exerted through the use of decision-aids. This finding has important implications regarding decision-aid development. Although some view decision aids as a tool to influence consumer purchasing behaviour [27], the technology also has the potential to inform consumer choices by providing information as to the true chances of winning or the risks associated with gambling [20,24]. For example, the use of decision-aids warning of the dangers of excessive gambling has been shown to reduce the instances of continued gambling (e.g., cases where individuals obtain extra funds to continue gambling) by up to $35 \%$ [51]. Decision-aids may be used to inform individuals of the benefits and risks involved in making online purchases [52].

\section{CONSUMER PROTECTION}

The findings of the present study also highlight the need to ensure that such technology is not used to take advantage of decision-makers $[53,54]$. In order to maintain a transparent and sustainable industry it is necessary to protect consumers [53, 54]. As previously stated, recent technological advancements, specifically regarding mobile commerce and mobile internet browsing, allow for the provision of location-aware, personalised messages to be sent to individuals with the aim of influencing event attendance, product purchases and even general behaviour without fully informing individuals of the harm and risk involved [1, 17, $18,55]$. One example of this is subscriptions to mobile applications or services, where the phone call can also be a mechanism for funds transfer. For instance missed call scams encourage phone calls, but may not properly inform the consumer as to the higher cost of the phone call. This can be a particular concern where such technology is used to target young people and children. The present study indicates that decision aids can be used to encourage or warn consumers.

The present study indicated that people's behaviour can be influenced by decisional support and online advice, but the trust we place in computers is no longer appropriate. Not all online advice is sound. For instance collaborative filters are vulnerable to attempts to influence [19]. Repeated positive (or negative) ratings of a product can be submitted to influence recommendations (Shilling attacks), and attempts are being made to protect such filters by requiring that one person (or IP address) has one vote.

Unfortunately purveyors of spam may mimic reputable sources, seeking to make offers that people have difficulty refusing. The present study indicates a number of vulnerabilities to decisional support. Time pressure and risk may influence the response to online advice. In the present study people appeared to think less under higher risk, a tendency for poorer decision making under time pressure could be construed as panic [30,41] and such a tendency for reduced thought seems to be exacerbated by advice urging risk taking (i.e. hit advice) in the present study. Indeed compliance with good advice (e.g. do not click on links on emails) may be less when a situation is construed as low risk (e.g. when the spam mimics a service provider). 


\section{LIMITATIONS}

The present study addressed time pressure, because the speed of the operator can be linked to productivity and profits. To introduce the element of time pressure response deadlines were implemented, after which time default responses were registered. This is in keeping with dealing procedures in casinos where minimum bets are required to stay in the game, and the casino may deal cards if the player does not supply clear responses. The present paper analysed overall performance, and included defaulted trials. When analysed without the defaulted trials, the effects of time pressure were reduced, but the pattern of findings involving risk and advice remain the same, although effects were actually more significant.

The present study used simulated gambling as a laboratory paradigm to address online influence. Indeed, there is a long tradition of using gambling-like tasks to study decision making and this is done for purposes of tractability. It can be difficult to portray more naturalistic real-life decision making-tasks as the correct responses and successful outcomes may be more difficult to determine [56]. However, we acknowledge that actual gambling for money outside the laboratory may elicit higher levels of arousal [57], and also note that those features (risk, time pressure) that may hinder effective decision making may sometimes appeal to gamblers.

\section{CONCLUSION}

The present study considered whether a decision-aid could influence individuals toward a specific alternative in real-time. By highlighting "standing" or "hitting" a decisionaid was capable of persuading individuals towards greater caution or risk. Greater compliance with an aid may occur at higher risk. Decision aids can encourage or caution a consumer, but time pressure and greater risk can reduce consumer thought. Decision-aid technology can be utilised for online product recommendations [52] or provision of information as to the risks of gambling [23]. Decision-aid technology may be used to persuade individuals to engage in activities or buy products in real-time but there remain concerns as to whether consumers will be properly cognisant of the consequences when they comply with a decision aid.

\section{ACKNOWLEDGEMENTS}

The authors would like to acknowledge funding support from Gambling Research Australia (Tender 178/06).

\section{REFERENCES}

[1] Mahatanankoon P, Wen HJ, Lim B. Consumer-based m-commerce: exploring consumer perception of mobile applications. Comput Standards Interfaces 2005; 27: 347-57.

[2] Nielsen J. Designing web usability. Indianapolis: New Riders Publishing 2000.

[3] Eadington WR. The future of online gambling in the United States and elsewhere. J Public Policy Market 2004; 23: 214-9.

[4] Griffiths MD. Internet gambling: issues, concerns and recommendations. Cyberpsychol Behav 2003; 6: 557-68.

[5] Griffiths MD, Parke A. Why internet gambling prohibition will ultimately fail. Gambl Law Rev 2004; 8: 295-9.

[6] Chirqui JF, Ribisl KM, Wallace RM, Williams RS, O'Connor JC, Arculli R. A comprehensive review of state laws governing Internet and other delivery sales of cigarettes in the United States. Nicotine Tob Res 2008; 10: 253-65. marketing. ACM Trans Web 2007; 1: 1-39.

[16] Schafer JB, Konstan JA, Riedl J. E-commerce recommendation applications. Data Mining Knowl Disc 2001; 5: 115-53.

[17] Mahatanankoon P, Vila-Ruiz J. Why won't consumers adopt mcommerce? An exploration study. J Internet Commerce 2007; 6: 113-28.

[18] Yang WS, Cheng HC, Dia JB. A location-aware recommender system for mobile shopping environments. Expert Syst Appl 2008; 34: 437-45.

[19] Lam SK, Frankowski D, Riedl J. Do you trust your recommendations? An exploration of security and privacy issues in recommender systems. Lect Notes Comp Sci 2006; 3995: 14-29.

[20] Monaghan S. Responsible gambling strategies for internet gambling: the theoretical and empirical base of using pop-up messages to encourage self-awareness. Comput Hum Behav 2009; 25: 202-7.

[21] Phillips JG, Ogeil RP, Blaszczynski A. Human factors determining consumer response to recommenders. In: Columbus F, Ed. Advertising: types, trends and controversies. New York: Nova Science Publishers (in press).

[22] Monaghan S, Blaszczynski A. Recall of electronic gaming machine signs: a static versus a dynamic mode of presentation. J Gambl Issues 2007; 20: 253-68.

[23] Monaghan S. Review of pop-up messages on electronic gaming machines as a proposed responsible gambling strategy. Int J Ment Health Addict 2008; 6: 214-22.

[24] Blaszczynski A, Ladouceur R, Nower L, Shaffer HJ. Informed choice and gambling: Principles for consumer protection. Melbourne, Australia: Australian Gaming Council 2005

[25] Brody RG, Kowalczyk TK, Coulter JM. The effect of a computerized decision aid on the development of knowledge. J Bus Psychol 2003; 18: 157-74.

[26] Haubl G, Murray KB. Preference construction and persistence in digital marketplaces: the role of electronic recommendation agents. J Consum Psychol 2003; 13: 75-91.

[27] Gretzel U, Fesenmaier DR. Persuasion in recommender systems. Int J Electron Commerce 2007; 11: 81-100.

[28] Gershoff AD, Mukherjee A, Mukhopadhyay A. Consumer acceptance of online agent advice: extremity and positivity effects. J Consum Psychol 2003; 13: 161-70.

[29] Vickers D. Decision Processes in Visual Perception. London: Academic Press 1979.

[30] Janis IL, Mann L. Emergency decision making: a theoretical analysis of responses to disaster warnings. J Hum Stress 1977; 3: 35-45.

[31] Phillips JG, Amrhein PC. Factors influencing wagering in simulated Blackjack. J Gambl Behav 1989; 5: 99-111.

[32] Thorp E. Beat the dealer. New York: Vintage 1966.

[33] Wagenaar W. Paradoxes of gambling behaviour. East Sussex, England: Erlbaum 1988.

[34] Chau AWL, Phillips JG, von Baggo KL. Departures from sensible play in computer blackjack. J Gen Psychol 2000; 127: 426-38. 
[35] Seale DA, Phelan SE. Bluffing and betting behavior in a simplified poker game. J Behav Decis Making 2009, DOI: 10.1002/bdm 658.

[36] Gino F, Moore DA. Effects of task difficulty on use of advice. J Behav Decis Making 2007; 20: 21-35.

[37] Horst M, Kuttschreuter M, Gutteling JM. Perceived usefulness, personal experiences, risk perception and trust as determinants of adoption of e-government services in The Netherlands. Comput Hum Behav 2007; 23: 1838-52.

[38] Swaminathan V. The impact of recommendation agents on consumer evaluation and choice: the moderating role of category risk, product complexity, and consumer knowledge. J Consum Psychol 2003; 13: 93-101

[39] Kerstholt JH. Decision making in a dynamic situation: the effect of false alarms and time pressure. J Behav Decis Making 1995; 8: 181-200

[40] Goodie AS, Crooks CL. Time-pressure effects on performance in a base-rate task. J Gen Psychol 2004; 131: 18-28.

[41] Mann L, Burnett P, Radford M, Ford S. The Melbourne decision making questionnaire: an instrument for measuring patterns of coping with decisional conflict. J Behav Decis Making 1997; 10: 1-19.

[42] Rieskamp J, Hoffrage U. Inferences under time pressure: how opportunity costs affect strategy selection. Acta Psychol (Amst) 2008; 127: 258-76.

[43] Sarter NB, Schroeder B. Supporting decision making and action selection under time pressure and uncertainty: the case of in flight icing. Hum Factors 2001; 43: 573-83.

[44] Todd P, Benbasat I. Inducing compensatory information processing through aids that facilitate effort reduction: an experimental assessment. J Behav Decis Making 2000; 13: 91-106.

[45] Hannum RC, Cabot AN. Practical Casino Math. Las Vegas, Nevada: Trace Publications 2005.

[46] Walker MB, Sturevska S, Turpie D. The quality of blackjack play in Australian casinos. In: O'Connor J, Ed. High Stakes in the Nineties: Sixth National Conference of the National Association for
Gambling Studies (pg. 193-202). Fremantle, Australia: Curtin University 1995.

[47] McSherry D. Explanation in recommender systems. Artif Intell Rev 2005; 24: 179-97.

[48] Jungermann H, Fischer K. Using expertise and experience for giving and taking advice. In: Betsch T, Haberstroh S, Eds. The routines of decision making. New Jersey: Lawrence Erlbaum 2005; pp. 157-74.

[49] $\mathrm{Pu} \mathrm{P}$, Chen L. Trust-inspiring explanation interfaces for recommender systems. Knowl Based Syst 2007; 20: 542-56.

[50] O'Hare M, Phillips JG, Moss S. The effect of contextual and personal factors on the use of recommenders in e-Markets. Ergon Open J 2009; 2: 207-16.

[51] Benhsain K, Taillefer A, Ladouceur R. Awareness of independence of events and erroneous perceptions while gambling. Addict Behav 2004; 29: 399-404

[52] Senecal S, Nantel J. The influence of online product recommendations on consumers' online choices. J Retail 2004; 80: 159-69.

[53] Blaszczynski A, Ladouceur R, Nower L, Shaffer H. Informed choice and gambling: Principles for consumer protection. J Gambl Bus Econ 2008; 2: 103-18.

[54] Blaszczynski A, Ladouceur R, Shaffer H. A science-based framework for responsible gambling: the Reno model. J Gambl Stud 2004; 20: 301-17.

[55] Yuan ST, Tsao YW. A recommendation mechanism for contextualized mobile advertising. Expert Syst Appl 2003; 24: 399414.

[56] Herek GM, Janis I, Huth P. Decision making during international crisis: is quality of process related to outcome? J Conflict Resolut 1987; 31: 203-6.

[57] Anderson G, Brown RIF. Real and laboratory gambling, sensation seeking, and arousal. Br J Psychol 1984; 75: 401-10.

(C) Phillips et al.; Licensee Bentham Open.

This is an open access article licensed under the terms of the Creative Commons Attribution Non-Commercial License (http: //creativecommons.org/licenses/ by-nc/3.0/) which permits unrestricted, non-commercial use, distribution and reproduction in any medium, provided the work is properly cited. 